\title{
Recurrent Axillary Giant Lipoma: A Rare Case Report.
}

\author{
Akshay Baid ${ }^{(1)}$, Pranab Jain ${ }^{(1)}$, Sanjay Pandey ${ }^{(2)}$, Ritesh Ranjan ${ }^{(3)}$, \\ Krishnamurty $^{(3)}$, Sandeep Kansal ${ }^{(3)}$, Mamta Gupta ${ }^{(4)}$ \\ ${ }^{1}$ Junior Resident, Department of General Surgery. \\ ${ }^{2}$ Professor, Department of General Surgery. \\ ${ }^{3}$ Assistant Professor, Department of General Surgery. \\ ${ }^{4}$ Associate Professor, Department of Pathology.
}

\begin{abstract}
Lipomas are benign tumours and are most common mesenchymal soft tissue tumours, which are composed of lipocytes. Usual sites of occurrence are trunk and extremities. Axilla is very unusual site of lipoma, giant lipomas being very rare. We report a case of Recurrent giant lipoma in left axilla extending upto root of neck superiorly, scapular region posteriorly and underneath Pectoralis major \& minor muscle.
\end{abstract}

\section{Introduction}

Lipomas are very slow growing, most common mesenchymal tumours with an estimated incidence of nearly $10 \%$ in general population ${ }^{(1)}$. Giant lipomas are defined by Sanchez et al as size of atleast $10 \mathrm{~cm}$ in one dimension or weighs a minimum of about $1000 \mathrm{gms}^{(2)}$. Most of lipomas have diameter of around $2 \mathrm{~cm}$ and rarely they grow beyond $10 \mathrm{~cm}^{(3)}$. Patient usually seek treatment due to social embarrassment resulting from the inability to properly wear clothes along with limitations of functions. We report an unusual case of Recurrent Lipoma in left axillary region spreading upto scapular region.

\section{Case Report}

A $15 \mathrm{yr}$ old boy presented with complaints of swelling on left axillary region since 9 yrs, which was progressive in nature without any other symptoms and loss of functions. There were two scar marks of previous surgeries. Excision of similar swelling was done earlier twice, 9 and 8 yrs back, from axilla and scapular region respectively (Figure $1 \& 2$ ).

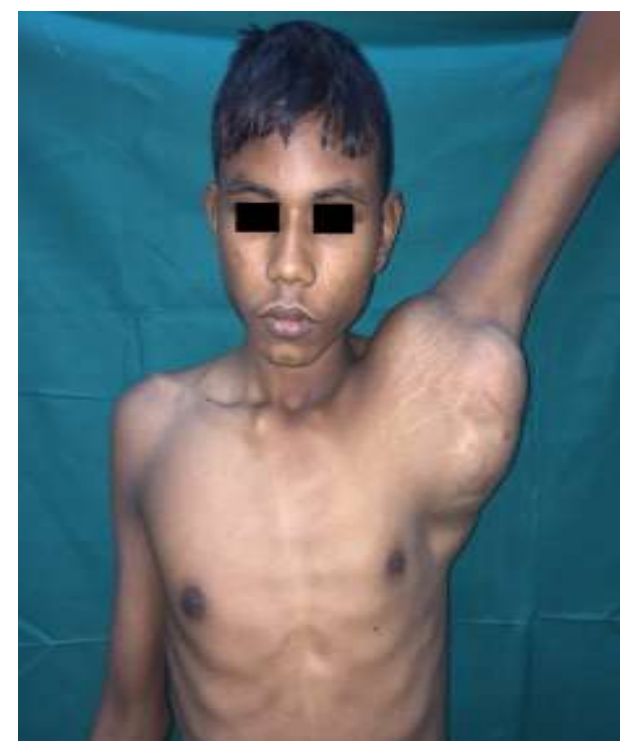

Figure 1 : Pre-operative image showing giant left axillary lipoma.

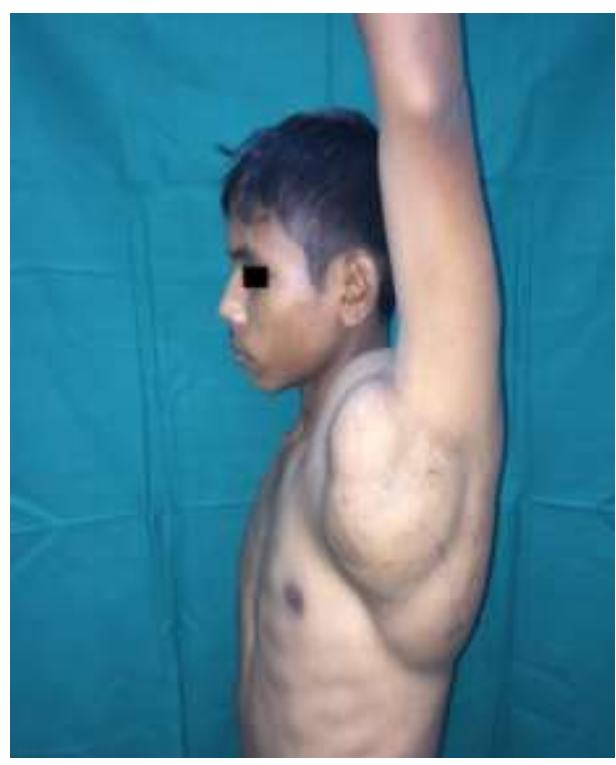

Figure 2 : Pre-operative image showing giant left axillary lipoma.

On examination, a lump of around $16 \times 19 \mathrm{cms}$ was present in and around left axilla, soft in consistency, non tender with positive sign of fluctuation. No skin changes were noted and Brachial, radial \& ulnar pulsations were felt normal. Neurological examination was also normal \& power of left upper limb was also normal (grade

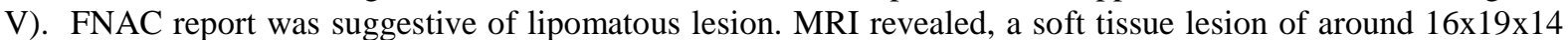
$\mathrm{cms}$, extending superiorly above the clavicle in the root of neck, anterolaterally to shaft of humerus, posteriorly 
invaginating in left subscapularis muscle \& anteriorly invaginating both Pectoralis major and minor muscle. It also stated compression of lateral wall of chest towards contralateral side (Figure 3). Evidence of involvement of any bone, neurovascular bundle, intrapleural extension was absent.

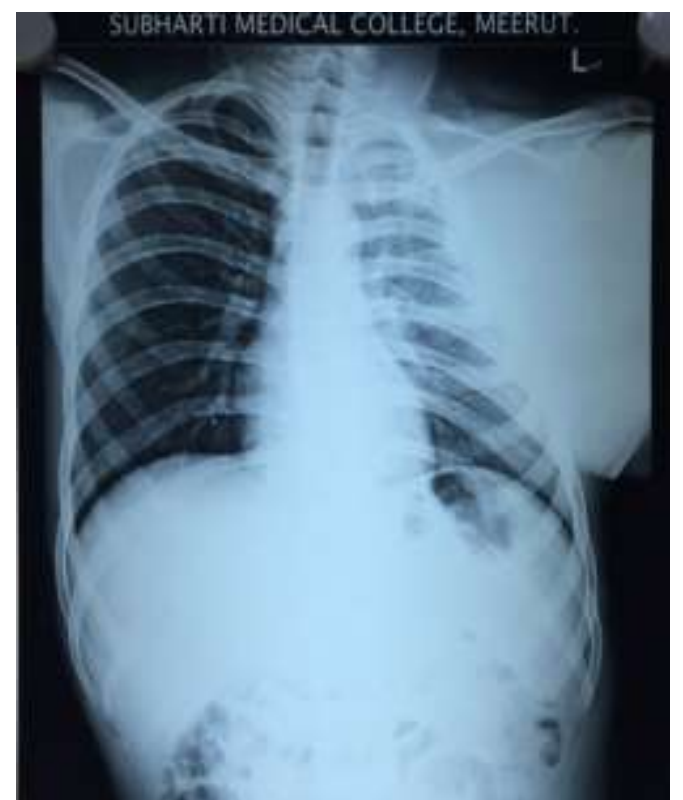

Figure 3 :X-Ray showing compression of rib cage medially.

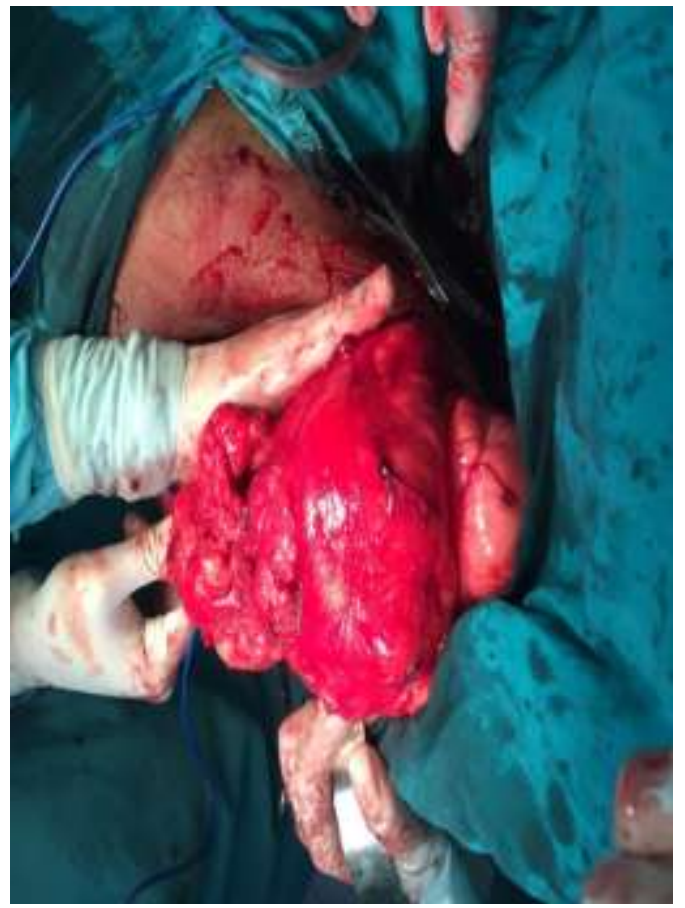

Figure 5 :Intra-operative image showing excision of giant lipoma.

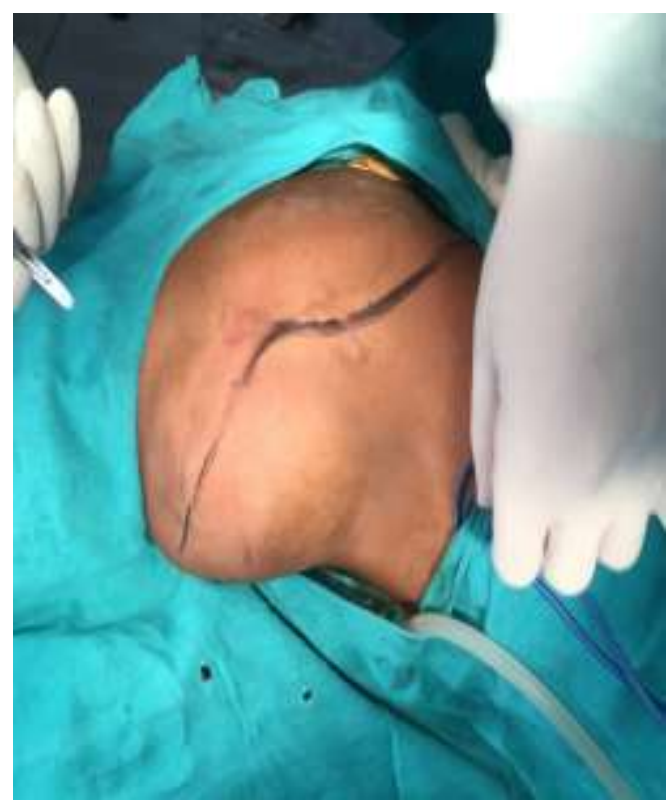

Figure 4 : S shaped incision given.

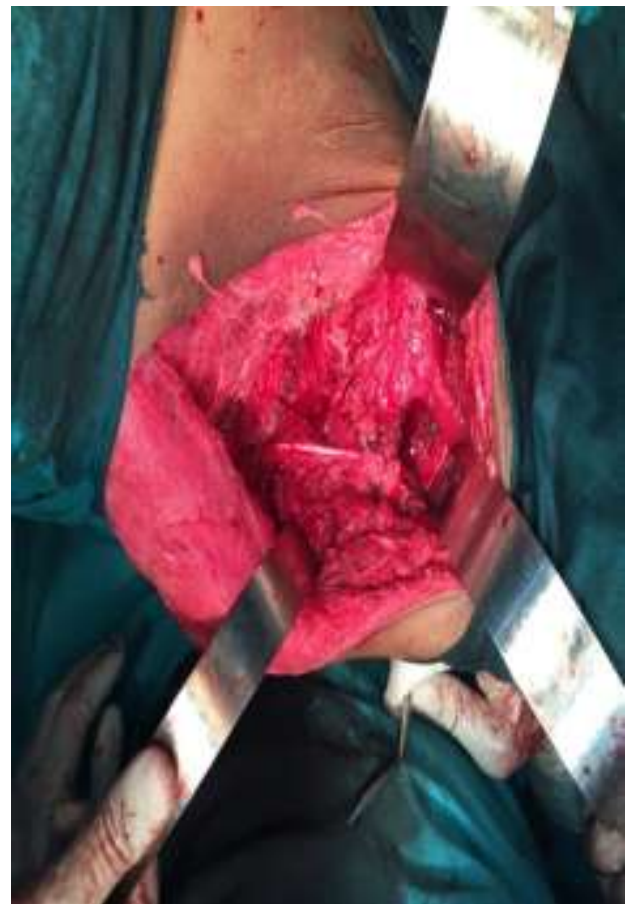

Figure 6 : Intra operative image after excision of giant lipoma. 
Surgery was planned. A S - shaped incision was given over the swelling (Figure 4). Skin flaps were raised and swelling was meticulously resected from all muscle plains (Figure $5 \& 6$ ). It was adhered to capsule of shoulder joint which was opened. Swelling was excised and capsule was repaired. Wound was repaired over suction drains. Post-op period was uneventful. Drains were removed on $4^{\text {th }}$ day. Patient regained all movements normally and was discharged after removing stitches on post-op day 10 (Figure $7 \& 8$ ).

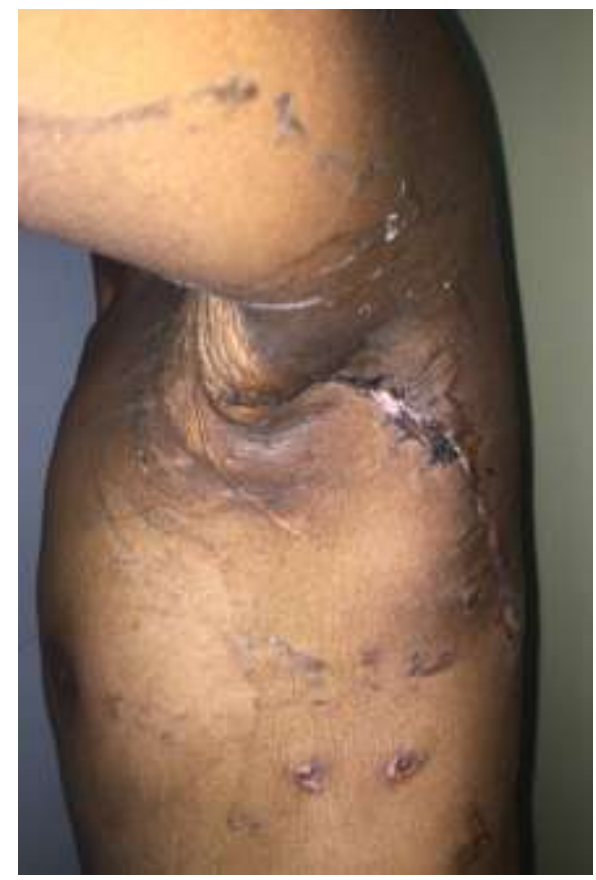

Figure 7 :Post-operative image after excision of lipoma.

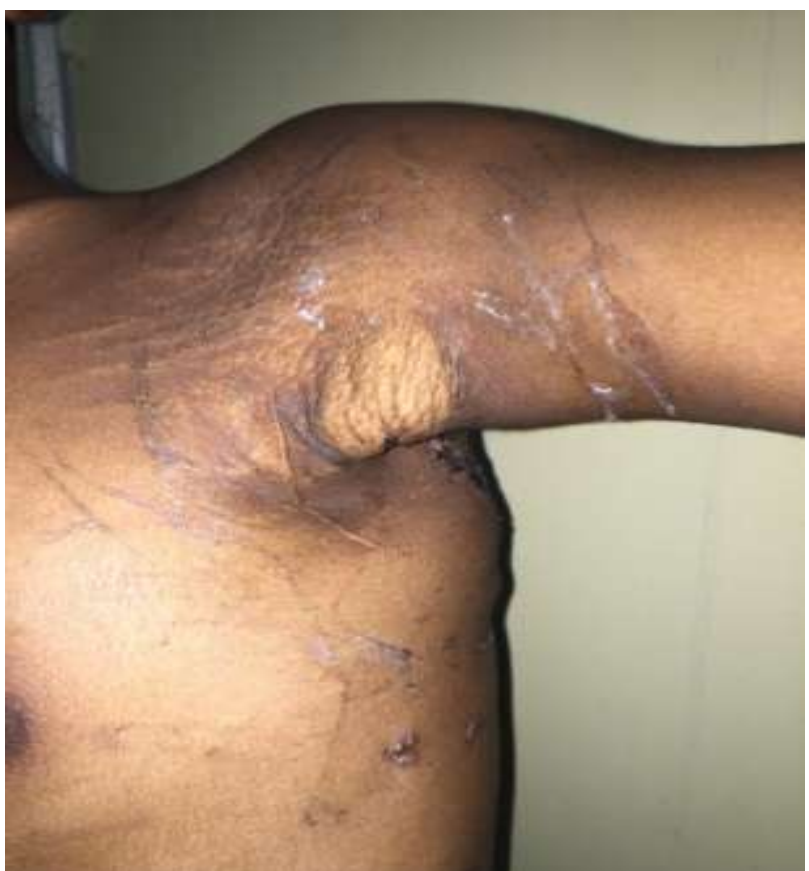

Figure 8 : Post-operative image after excision of lipoma.

\section{Discussion}

Lipomas are most common mesenchymal tumours that can occur in all parts of body with an incidence of $10 \%$ and are mainly composed of adipose cells. They may be referred to as fibrolipomas due to presence of fibrous septae. Lipoma can be found in almost all organs of body where fat normally exists and are therefore called as ubiquitous or 'Universal tumours ${ }^{,(4)}$. Lipomas have also been described in internal organs such as liver, 
lungs, kidney, uterus etc. where little or no adipose cells are found ${ }^{(5)}$. Lipomas can be solitary or occur in multiples and can also occur alone or in association of other syndromes. They are usually located in the trunk or extremities, however, they can also be interosseus, visceral, intramural, subfascial or intermuscular. These are considered 'most innocent of tumours' as rarely they cause any symptoms. However, large internal lipomas can produce abdominal pain, kidney failure or other systemic complications and also may undergo sarcomatous transformation $^{(3)}$.

Giant axillary lipomas have been rarely reported in the literature. Giant lipomas although rare, can present in thigh, shoulder or trunk. Giant lipomas of the axilla are very rare ${ }^{(6)}$. In 1996, De Andrade presented 31 cases of axillary masses and only 1 case of axillary lipoma was reported ${ }^{(7)}$. This relatively low frequency of axillary lipomas is probably underestimated due to the fact that most of the lipomas of the axilla are more classical in their size and then escape to scientific reports. Nevertheless, giant lipomas of the axilla remain really infrequent. The axillary region is a specific localization for hibernoma that is rare soft tissue tumour of brown fat differentiation ${ }^{(8)}$. The mechanism of uncontrolled growth of such lipomas remain unclear. However it was proposed that after a blunt trauma, rupture of fibrous septaes(preventing migration of fat) accompanied by tears of the anchorage between the skin and deep fascia may result in local proliferation of adipose tissue ${ }^{(9)}$. Since axillary region is one of the most movable of body, it can be exposed to microtrauma with each movement of the upper $\operatorname{limb} b^{(9,10)}$.

The excised lipoma weighed about 2000 gms (Figure 9), with dimensions of about 16x19x14 cms. The records of previous excised swelling is unavailable. Likely, the previous swelling was not been excised completely, some part of which was left behind, as it was growing under the muscle plane, suggestive of recurrence. Along with FNAC, MRI was done to look for extension around axilla, humerus, clavicle, as also, the swelling was too large such that it was compressing the rib cage away from the axilla.

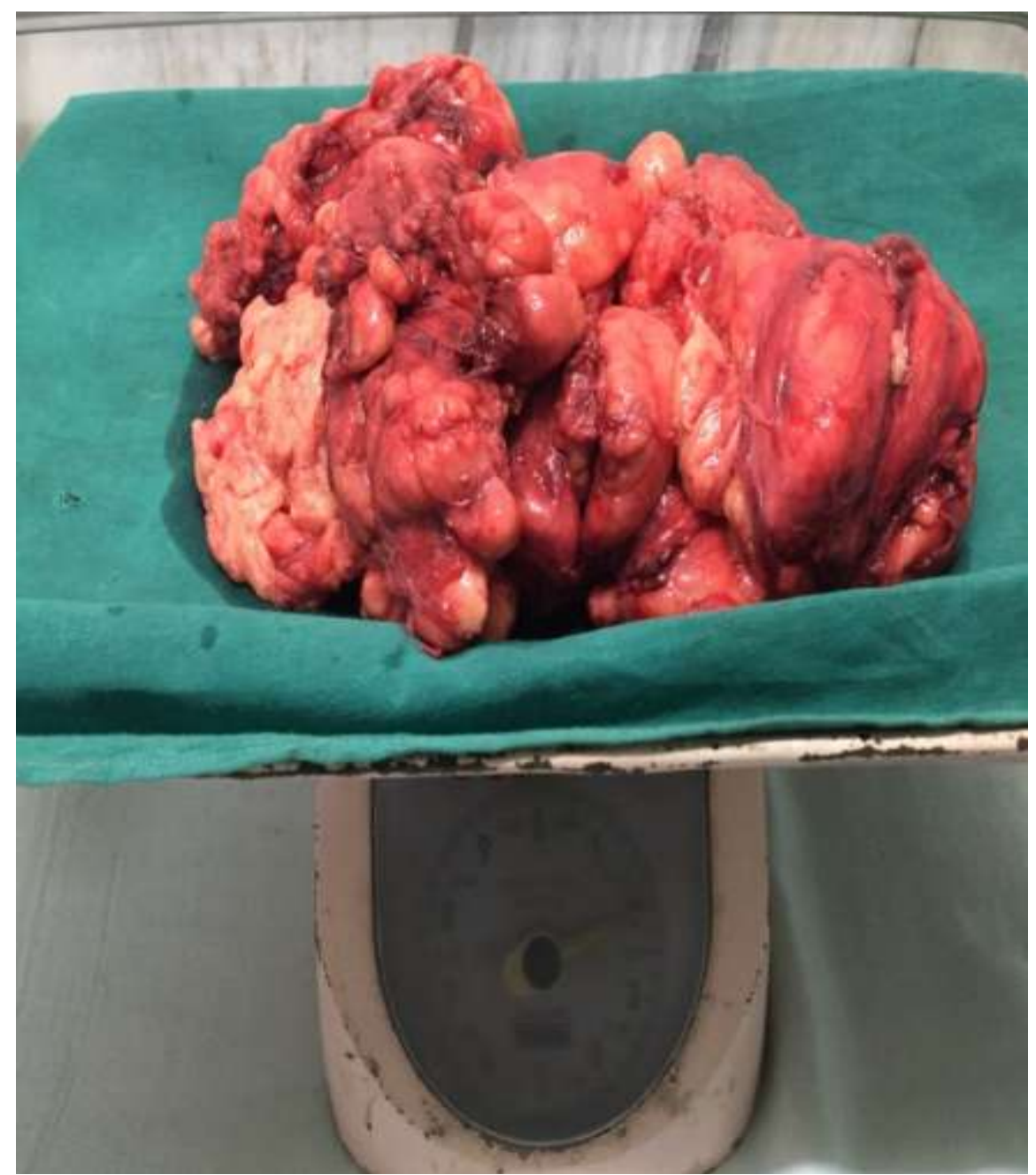

Figure 9 : Excised lipomatous mass weighing around 2000 gms. 
A definitive diagnosis of giant lipoma can be made only by histopathological examination. In our case Histopathology report was suggestive of lobules of fibroadipose tissue along with entrapped partially atrophic skeletal muscle fibres in between (Figure 10). However, once suspected, other investigations can provide additional information about the tumour. The characteristics of benign lipomas on USG, CT \& MRI have been well established and technetium-99 diethylene-triamine-pentaacetic acid scanning has also been used to confirm the diagnosis ${ }^{(11,12)}$.

Surgery is the treatment of choice for these giant swellings due to their size, tendency to recur and the potential hazard of malignant transformation ${ }^{(13)}$. Recently suction assisted lipectomy and liposuction have been reported as effective treatment of giant lipomas ${ }^{(14)}$.

However large hematoma formation and recurrence which occur due to incomplete removal are common complications of liposuction in such an indication ${ }^{(14)}$.

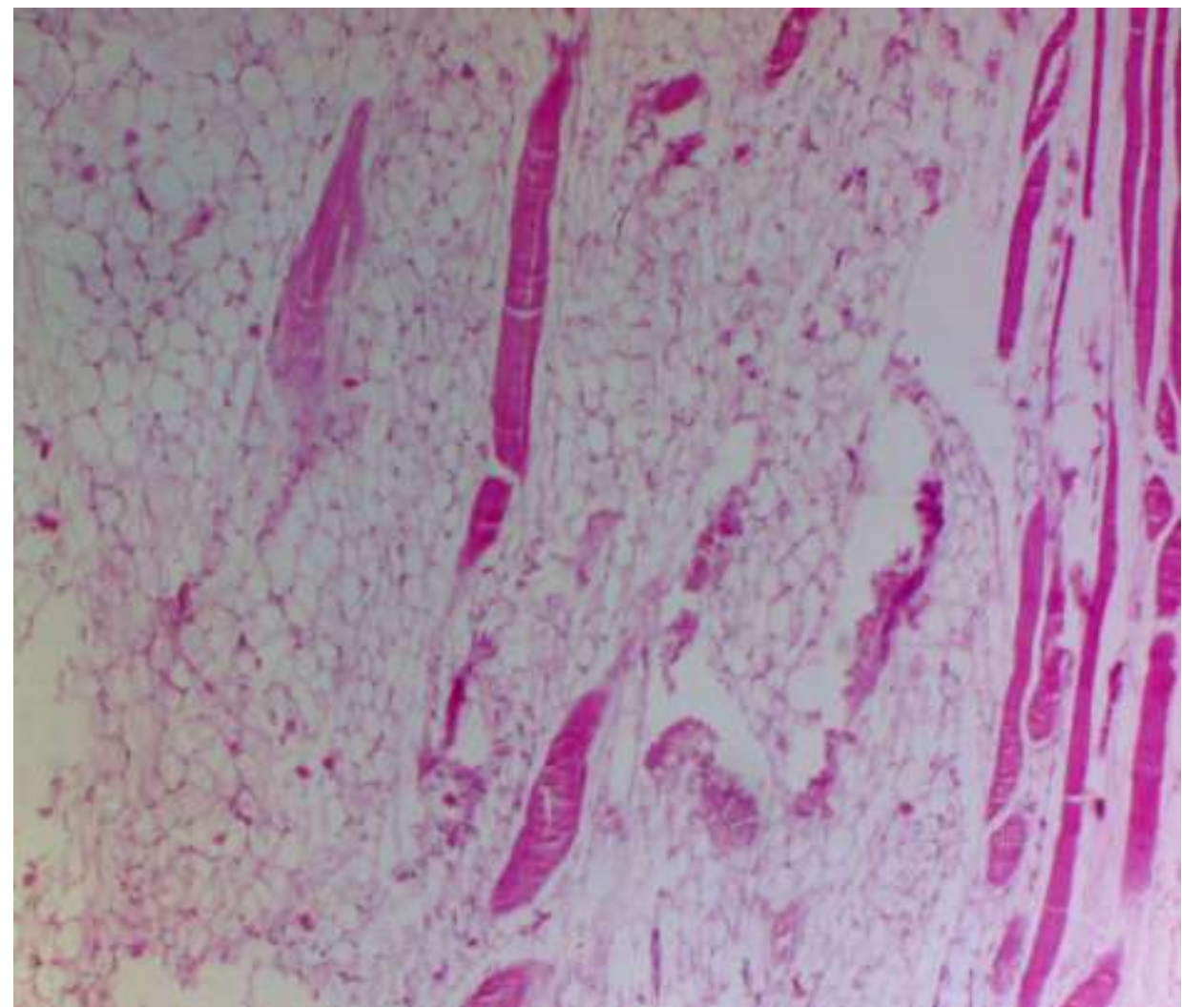

Figure 10 : Histopathology slide suggestive of lobules of fibroadipose tissue with partially entrapped skeletal muscle fibres seen.

In our knowledge surgical excision as a whole is still the best management for giant axillary lipomas where large vessels and nerves could be engulfed by the neoplasm and also to offer a better control on local recurrences.

\section{References}

[1]. Meson H. Lipoma in clinical dermatology. Clin dermatol, 1991, 4:1-2

[2]. Sanchez Giant lipomaL case report and review of the literature. J Am Acad Dermatol 1993; $28: 266$.

[3]. Enzinger F.M.,Weiss S.W. Soft tissue tumours. St Louis: CV Mosby, 1988, pp.301-345.

[4]. Davis C Jr, Gruhn JG. Giant lipoma of the thigh. Arch Surg 1967;95;151-6.

[5]. Lanza G(1985) Anatomia Patologica Sistematica, $2^{\text {nd }}$ ed. Piccin, p. 2262.

[6]. Vandeweyer E, Scagnol I. Axillary Giant Lipoma: A case report. Acta Chir Belg 2005; 105:656-7.

[7]. De Andrade J.M., Marana H.R., Sarmento Fihlo J.M., Murta E.F., Velludo M.A., Bighetti S. Differential diagnosis in axillary masses. Tumori, 1996, 82:596-600.

[8]. Lay K., Velasco C., Akin H., Mancini M. Axillary hibernoma : an unusual soft tissue tumour. Am Surg, 2000, 66:787-91.

[9]. Copcu E., Sivrioglu N.S. Posttraumatic Lipoma : analysis of 10 cases and explanation of possible mechanisms. Dermatol Surg, 2003, 29:215-9.

[10]. Copcu E. Axillary Giant Lipoma. Plast Reconstr Surg, 2004, 114:1982-3.

[11]. Wolfe SW, Bansal M, Heely JH, et al. Computed tomographic evaluation of fatty neoplasms of extremities. A clinical radiographic and histologic review of cases. Orthopedics 1989;12:1351-8. 
[12]. Sundram M. Baran G, Merenda G, Mcdonald DJ. Myxoid liposarcoma: Magnetic resonance imaging appearance and clinical and histological correction. Skeletal Radiol 1990; 19:359-62.

[13]. Terzioglu A, Tuncali D, Yuksel A, Bingul F, Aslan G. Giant lipoma: A series of 12 consecutive cases and a giant liposarcoma of thigh. Dermatol Surg 2004; 39:463-7.

[14]. Nichetr L.S., Gupta B.R. Liposuction in giant lipoma. Ann Plast Surg, 1990;24:362-5. 